\title{
EXTRACTION OF COLLAGEN FROM BY-PRODUCTS, DESIGNED TO INCREASE THE QUANTITY AND QUALITY OF PRODUCTION IN AGRICULTURE
}

\author{
MIHAELA-DOINA NICULESCU ${ }^{1}$, CARMEN GAIDĂU ${ }^{1}$, MARIUS BECHERITU ${ }^{3}$, \\ MĂDĂLINA IGNAT ${ }^{1}$, DORU GABRIEL EPURE ${ }^{2}$, MIHAI GIDEA ${ }^{3}$ \\ ${ }^{1}$ INCDTP - Division Leather and Footwear Research Institute (ICPI), 93 Ion Minulescu St, \\ Bucharest, Romania, mihaelaniculescu59@yahoo.com \\ ${ }^{2}$ SC Probstdorfer Saatzucht Romania SRL, 20 Siriului St, 1, Bucharest, Romania \\ ${ }^{3}$ University of Agronomic Science and Veterinary Medicine, 59, Marasti St, 1, Bucharest, \\ Romania
}

\begin{abstract}
Collagen polydispersions obtained by associated thermal and enzymatic processes for high-yield extraction of collagen from waste, under mild reaction conditions, are fit for application in agriculture. This study presents the possibility of using thermal and enzymatic processes of byproducts from fishing industry to obtain collagen extracts, to increase the quantity and quality of oilseeds and horticultural production. Collagen polydispersions were characterized by chemical and instrumental analyses: gravimetric, volumetric, potentiometry, IR spectroscopy, tensiometer methods, Dynamic Light Scattering (DLS). Analytical investigation has shown that: the collagen polydispersions have bioactive properties due to the content of small sized particles $(<100 \mathrm{~nm}$ range), such as free amino acids and oligopeptides, able to penetrate the cell membranes and seed coating; the larger sized particles (100-10000 nm ranges) such as polypeptides, ensure the bioactive deposit in the film matrix on the surface, with long term releasing ability; resistance of crosslinked film of fish gelatin for indehiscent treatment in rape crop. The synergy of collagen hydrophilicity, its known biodegradability, bio-active potential and film-forming properties recommend collagen polydispersions for applications in mixtures for treatment in agricultural crops.
\end{abstract}

Keywords: collagen by-products, surface properties, agriculture production.

\section{INTRODUCTION}

Since the main resource of collagen from the skin of terrestrial animals is susceptible to certain diseases (BSE, FMD), or is subject to religious restrictions when it comes to consumption, fish by-products as a source of collagen are an increasingly sought alternative, the more so as fish collagen has a lower phytotoxicity.

Fish processing generates a significant amount of waste, about $50-70 \%$ of the raw material (Pati et al., 2010; Bae et al., 2008), of which over 30\% is made up of skin, scales and bones, extremely rich in collagen, which is why it has attracted the attention of many researchers (Lee et al., 2001).

As expert studies show (Aberoumand, 2012), the methods used for isolating collagen from the skins of mammals are not effective enough for isolating collagen from marine resources, therefore, the processes of extracting collagen must be tailored to the resources and properties of collagen extracts, according to their applications (Gaidau et al., 2013; Lee et al., 2014).

However, thermal and enzymatic hydrolyses are the basic processes of extracting collagen from fish skin (Wang et al., 2013; Zhang et al., 2011).

To increase performance in obtaining collagen extracts from fish skin, processes can be improved by pre-treatment with ultrasound (Kim et al., 2013; Zeng et al., 2012), and by using a system of membrane ultrafiltration and nanofiltration (Kim, 2013; Picot et al., 2010) to obtain bioactive peptides with a controlled molecular weight and functional properties. 
Some properties required in various applications, for example elasticity of formed films, can be improved by the addition of crosslinking agents. Studies on improving the mechanical properties of fish skin collagen films (Liu et al., 2014) have led to a reduction of film hygroscopicity from $295 \%$ to $54 \%$, an increase in shrinkage temperature of the film $\left(73.9^{\circ} \mathrm{C}\right)$ and film stability in distilled water at normal temperature.

This paper presents experiments for extracting collagen from fish skin waste, compared with extracting collagen from by-products of bovine leather, tanned or untanned, applying thermal-enzymatic hydrolysis processes, in terms of parameters specific to each type of leather processed.

\section{EXPERIMENTAL PART}

\section{Materials}

Fish skin was obtained from Danube Research-Consulting SRL, Romania. The leather by-products originated from wet blue shavings or pelt with the following characteristics: $50-70 \%$ volatile matter, $0.5-12.5 \%$ total ash, $14-17 \%$ total nitrogen, aqueous extract $\mathrm{pH}$ value of 3.5-8.0, were obtained in Leather and Footwear Research Institute, Bucharest, Romania. Sodium hydroxide, acetic acid were products of SC Chimopar SA Romania. Alcalase 2.4L was obtained from Novozymes Denmark.

\section{Procedures}

For collagen extraction from fish skin (sample 1), an alkaline pretreatment with $\mathrm{Na} \mathrm{OH} 0.2 \mathrm{~N}$, acid pretreatment with $\mathrm{CH}_{3} \mathrm{COOH} 0.1 \mathrm{M}$, extensive washing, followed by thermal and enzymatic processing at $60 \pm 2^{\circ} \mathrm{C}$ during 6 hours at atmospheric pressure, for collagen hydrolysate obtaining (sample 2).

The method for collagen extraction from bovine pelt as gelatin (sample 3) and hydrolysate (sample 4) were conducted at $80^{\circ} \mathrm{C}$. The method for collagen hydrolysate from wet blue shavings (sample 5) were conducted at $65-85^{\circ} \mathrm{C}$ with $\mathrm{Ca}(\mathrm{OH})_{2}$ and Alcalase 2.4L for 6 hours (Niculescu and Gaidau, 2014).

To cross-link the fish skin collagen extracts, $2 \mathrm{~mL} / \mathrm{L}$ glycerol and $2 \mathrm{~mL} / \mathrm{L}$ glutaraldehyde solution was used in concentration of $15 \mathrm{~g} / \mathrm{L}$ collagen (Liu et al., 2014).

\section{Analytical Methods}

The collagen polydispersions were analysed in terms of dry substance and total ash by gravimetric methods, total nitrogen and protein substance, aminic nitrogen by volumetric methods, hydroxyproline content by spectrophotometry according to SR 13385/1997 and other amino acid composition by high-performance liquid chromatography (HPLC with Thermo Electron, Finningen Surveier with DAD detector), according to SR EN ISO 13903, pH by potentiometric method, molecular weight by SDS-PAGE electrophoresis. Particle size and distribution was determined by ZetaSizer device Nano ZS (Malvern, UK).

\section{RESULTS AND DISCUSSIONS}

The intermediary and final collagen extracts (gelatins and hydrolysates), described in Table 1, was assessed by chemical and instrumental analyses. 
ICAMS $2016-6^{\text {th }}$ International Conference on Advanced Materials and Systems

Table 1. Description of collagen extracts samples

\begin{tabular}{clllll}
\hline Sample code & Sample 1 & Sample 2 & Sample 3 & Sample 4 & Sample 5 \\
\hline Description & Gelatin & Collagen & Gelatin & Collagen & Collagen \\
& from fish & hydrolysate & from & hydrolysate & hydrolysate \\
& skin & from fish & bovine & from bovine & from wet \\
& & gelatin & pelt & gelatin & blue shaving \\
\hline
\end{tabular}

Results of analyses performed in order to establish the chemical composition of collagen extracts are presented in Table 2.

Table 2. Physical-chemical characteristics of collagen extracts

\begin{tabular}{llccccc}
\hline No. & Characteristics, MU & Sample 1 & Sample 2 & Sample 3 & Sample 4 & Sample 5 \\
\hline 1 & Dry substance, \% & 4.47 & 4.40 & 8.46 & 10.85 & 8.45 \\
2 & Total ash, \% & 0.67 & 4.09 & 0.47 & 5.53 & 7.57 \\
3 & Total nitrogen, \% & 14.76 & 14.77 & 15.60 & 15.48 & 15.03 \\
4 & Protein substance, \% & 82.95 & 83,01 & 87.67 & 87.00 & 84.47 \\
5 & Amino nitrogen, \% & 0.32 & 0.99 & 0.20 & 0.94 & 2.10 \\
6 & pH & 6.35 & 7.94 & 3.70 & 7.56 & 8.31 \\
\hline
\end{tabular}

Under laboratory conditions, the yields of extraction of nitrogen from skin were from $80.97 \%$ for the extraction of fish skin as gelatin, up to $90.90 \%$ for the extraction of the gelatin from bovine leather and $93.70 \%$ for hydrolysate extraction from tanned bovine leather.

As expected, the collagen hydrolysate derived from tanned skin (sample 5) has a higher value for ash, but also a higher amino nitrogen content compared with hydrolysates from gelatin (sample 4, sample 2). Amino nitrogen content of collagen hydrolysates is in strict correlation with average molecular weight, an important property of collagen extracts. In general, the average molecular weight of collagen hydrolysates is below $20 \mathrm{kDa}$. For experimental hydrolysates of collagen extracted by direct hydrolysis from tanned bovine leather (sample 5), according to Sörensen Method, amino nitrogen content of $2.10 \%$ indicates an average molecular weight of 2200 Daltons, while for the extracted collagen hydrolysates obtained by hydrolysis of gelatin, amino nitrogen content of $0.94 \%$ and $0.99 \%$ indicates much higher average molecular weights, of 13,800 Daltons and 13,000 Daltons, respectively. Large differences between the average molecular weights for untanned hide hydrolysates compared to tanned leather hydrolysates reveal that the destruction of links between the tanning agent and the collagen matrix during hydrolysis leads to fragmentation of polypeptides and getting a broader polydispersity. Previous research (Niculescu and Gaidau, 2014; Niculescu et al., 2015) has shown, by means of HPLC analysis, that collagen hydrolysates with average molecular weight of up to 15,000 Daltons contain $4-8 \%$ free amino acids (histidine, alanine, glutamic acid, arginine, glycine, leucine, isoleucine, methionine, aspartic acid, valine, proline) and oligopeptides (phenylalanine/leucine, isoleucine/lysine) imparting bioactive properties to polydispersions.

The presence of very small components, such as free amino acids and oligopeptides, was emphasized by measurements with the ZetasizerNano ZS equipment, Malvern, for determining particle size and distribution, presented in histograms in Figure 1. 


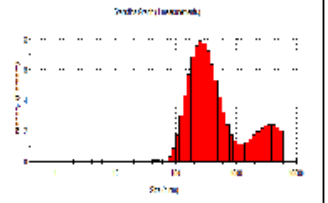

(a)

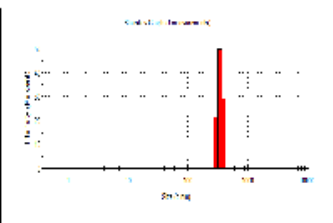

(b)

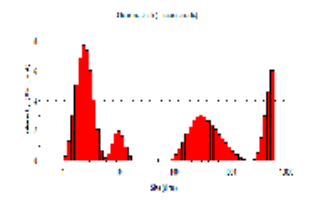

(c)

Figure 1. Particle size distribution in collagen hydrolysates obtained from:

(a) fish skin gelatin; (b) bovine hide gelatin; (c) tanned bovine leather

For collagen hydrolysates obtained from tanned leather, histograms highlight the presence of several types of compounds, with various particle size distributions, while for hydrolysates obtained from untanned bovine hide and fish skin, the number of compound types is limited and sizes range mainly over $100 \mathrm{~nm}$, which coincides with the presence of polypeptides, that give a higher average molecular weight, as indicated by amino nitrogen content. Table 3 presents the share of particle sizes in relation to size domains for analysed collagen hydrolysates.

Table 3. Share of particle sizes in collagen hydrolysates

\begin{tabular}{ccccc}
\hline \multirow{2}{*}{ Sample no. } & \multicolumn{5}{c}{ Share of particle sizes, \% } \\
& $1-10 \mathrm{~nm}$ & $10-100 \mathrm{~nm}$ & $100-1000 \mathrm{~nm}$ & $1000-5000 \mathrm{~nm}$ \\
\hline Sample 2 & - & 1.5 & 76.4 & 22.1 \\
Sample 4 & - & - & 100.0 & - \\
Sample 5 & 47.9 & 4.9 & 30.2 & 17.0 \\
\hline
\end{tabular}

The analytical results indicate that, under the technical conditions described in experimental models, hydrolysates with high polydispersity may be obtained, with a wide range of compounds in tanned bovine leather, or hydrolysates in the narrow domain with larger particles, from untanned bovine hides and fish skin.

FTIR-ATR spectral analysis revealed structural differences of the two types of collagen extracts, gelatin and hydrolysate: Figure 2 for collagen extracts from fish skin, Figure 3 for collagen extracts from untanned bovine hide gelatin.

Sample 1

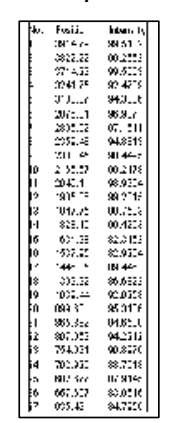

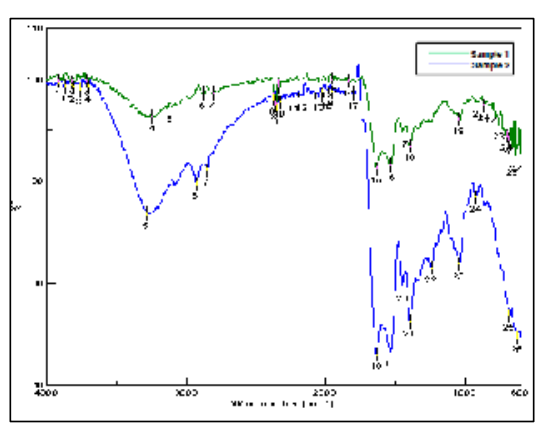

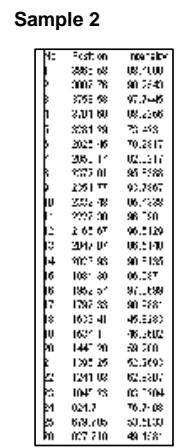

Figure 2. Comparative FT/IR spectra for gelatin and collagen hydrolysate derived from fish skin 


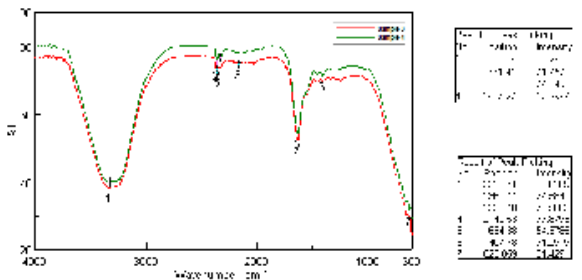

Figure 3. Comparative FT/IR spectra for gelatin and collagen hydrolysate derived from bovine hide

The experimental results confirm the spectral differences between the two types of collagen extracts, by the appearance of new peaks for hydrolysates compared to gelatin, at wavelengths of $2323.71 \mathrm{~cm}^{-1}, 2142.53 \mathrm{~cm}^{-1}, 1407.78 \mathrm{~cm}^{-1}, 623859 \mathrm{~cm}^{-1}$. However, in the range of $4000-3800 \mathrm{~cm}^{-1}$ and $1660-1600 \mathrm{~cm}^{-1}$, no significant differences occur, which confirms the predominantly peptidic structure of collagen hydrolysate derived from gelatin.

The presence of polypeptides is important for their known film-forming properties. Figure 4 presents the films of collagen extracted from fish skin, in the form of gelatin as such (a), gelatin with the addition of glycerol (b), and gelatin cross-linked with glutaraldehyde (c), and equivalent films (d), (e) (f), structured from fish collagen hydrolysate. The films obtained from raw collagen extracts are rigid and brittle, while the films made from extracts with the addition of glycerol, or crosslinked with glutaraldehyde are flexible and resilient.

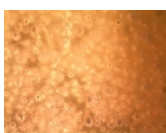

(a)

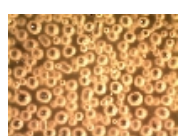

(b)

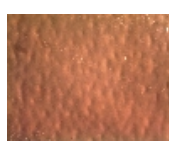

(c)

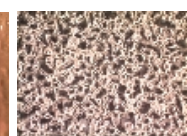

(d)

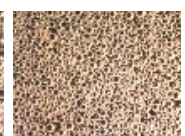

(e)

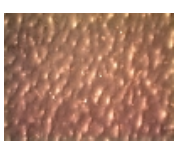

(f)

Figure 4. Optical microscopy (x20) of films: (a) gelatin; (b) additivated gelatin;

(c) cross-linked gelatin; (d) collagen hydrolysate; (e) additivated hydrolysate; (f) cross-linked hydrolysate

Figure 5 presents the dynamics of tensile strength tests for fish gelatin additivated with glycerol (sample 1A) and for fish gelatin additivated with glycerol and cross-linked with glutaraldehyde (sample 1B).

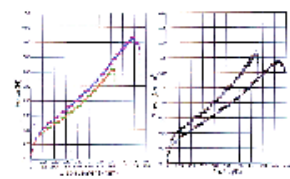

(a)

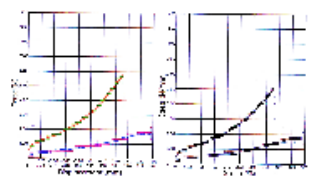

(b)

Figure 5. Tensile strength of collagen films: sample 1A; (b) sample 1B

The results confirm that collagen extracts are able to form films, whose flexibility, resilience and resistance can be changed depending on the degree of additivation using agents to improve flexibility and crosslinkers to increase resistance of films, to adapt them to the application requirements. 
Extraction of Collagen from By-products, Designed to Increase the Quantity and Quality of Production in Agriculture

\section{CONCLUSIONS}

The experimental processes for extraction of collagen from by-products resulted in gelatin and collagen hydrolysates with broad polydispersity, smart environmental products for applications in agriculture.

The collagen hydrolysates obtained from untanned bovine hides and fish skin contain mostly large-sized particles, exceeding $100 \mathrm{~nm}$, associated to polypeptides.

Collagen hydrolysates obtained from tanned bovine leather contain both large particles and small particles associated with free amino acids and dipeptides.

Gelatins and collagen hydrolysates are able to form films, and their flexibility, resilience and resistance can be improved by additivation and crosslinking.

\section{Acknowledgements}

The authors gratefully acknowledge the financial support of the ANCSI and UEFISCDI, Romania, in the framework of projects: PN 16.34.01.07 (contr. no. 26N/2016); RAPESTICK (contr. no. 162/2014); COLL_LEG_SEED (contr. no. 7/2016).

\section{REFERENCES}

Aberoumand, A. (2012), "Comparative Study Between Different Methods of Collagen Extraction from Fish and its Properties", World Applied Sciences Journal, 16(3), 316-319.

Bae, I., Osatomi, K., Yoshida, A., Osako, K., Yamaguchi, A., Hara, K. (2008), "Biochemical properties of acid-soluble collagens extracted from the skins of underutilised fishes", Food Chemistry, 108, 49-54.

Gaidau, C., Niculescu, M., Stepan, E., Epure, D.-G., Gidea, M. (2013), "New Mixes Based on Collagen Extracts with Bioactive Properties, for Treatment of Seeds in Sustainable Agriculture", Current Pharmaceutical Biotechnology, 14(9), 792-801.

Kim, H.K., Kim, Y.H., Park, H.J., Lee, N.H. (2013), "Application of ultrasonic treatment to extraction of collagen from the skins of sea bass Lateolabrax japonicas", Fisheries Science, 79(5), 849-856.

Kim, S.-K. (2013), Marine Proteins and Peptides. Biological Activities and Applications, John Wiley \& Sons, Ltd., New York, USA.

Lee, H.C., Singla, A., Lee, Y. (2001), "Biomedical applications of collagen”, International Journal of Pharmaceutics, 221, 1-22.

Lee, M.Y., Jo, Y.-J., Min, S.G., Hong, G.P. (2014), "Effects of High Pressure on the Porcine Placental Hydrolyzing Activity of Pepsin, Trypsin and Chymotrypsin", Korean Journal for Food Science of Animal Resources, 34(1), 14-19.

Liu, H.Y., Zhao, L., Guo, S.D., Xia, Y., Zhou, P. (2014), "Modification of fish skin collagen film and absorption property of tannic acid", Journal of Food Science and Technology-Mysore, 51(6), 11021109.

Niculescu, M.D., Becheritu, M., Gaidau, C., Epure, D.-G., Gidea, M., Stepan, E. (2015), "Extraction of collagen with bioactive properties for stimulation, nutrition and protection of plants", Proceedings of III International Leather Engineering Congress, Izmir, Turkey, 259-264.

Niculescu, M.D., Gaidau, C. (2014), "New Collagen Extracts Conditioning for Applications in Crop Protection Against Pests", Revista de Chimie, 65(12), 1457-1461.

Pati, F., Adhikari B., Dhara S. (2010), "Isolation and characterization of fish scale collagen of higher thermal stability", Bioresource Technology, 101, 3737-3742.

Picot, L., Ravallec, R., Fouchereau-Péron, M. et al. (2010), "Impact of ultrafiltration and nanofiltration of an industrial fish protein hydrolysate on its bioactive properties", Journal of the Science of Food and Agriculture, 90(11), 1819-1826.

Wang, W., Li, Z.L., Liu, J.Z., Wang, Y.J., Liu, S.H., Sun, M. (2013), "Comparison between Thermal Hydrolysis and Enzymatic Proteolysis Processes for the Preparation of Tilapia Skin Collagen Hydrolysate", Czech Journal of Food Sciences, 31(1), 1-4.

Zeng, J.N., Jiang, B.Q., Xiao, Z.Q., Li, S.H. (2012), "Extraction of Collagen from Fish Scales with Papain under Ultrasonic Pretreatment, Advanced Materials Research", 366, 421-424.

Zhang, F., Wang, A., Li, Z., He, S., Shao, L. (2011), "Preparation and Characterisation of Collagen from Freshwater Fish Scales", Food and Nutrition Sciences, 2, 818-823. 